\title{
"Substituent on Benzenesulfonyl Group" Effect in Use of 8-Benzenesulfonamidoquinoline Derivatives as Chelate Extractant
}

\author{
Naoki Hirayama, ${ }^{* \dagger}$ Noriko Sugisaka, $* *$ Junko Taga, $* *$ Syunichi Oshima, $* * *$ \\ and Takaharu HonJo* \\ *Department of Chemistry, Faculty of Science, Kanazawa University, \\ Kakuma-machi, Kanazawa 920-1192, Japan \\ **Division of Material Chemistry, Graduate School of Natural Science and Technology, \\ Kanazawa University, Kakuma-machi, Kanazawa 920-1192, Japan \\ ***Division of Basic Sciences, Graduate School of Natural Science and Technology, \\ Kanazawa University, Kakuma-machi, Kanazawa 920-1192, Japan
}

\begin{abstract}
"Substituent on benzenesulfonyl group" effect of 8-benzenesulfonamidoquinoline [ $N$-(8-quinolyl)benzenesulfonamide, $\mathrm{Hbsq}]$ as bidentate chelate extractant for divalent metal cations was investigated with using Hbsq and its eight derivatives. Introduction of electron-withdrawing substituent on the benzenesulfonyl group in Hbsq enhanced the extractability that originated from its inductive effect. Furthermore, $a$ bulky substituent on an ortho-position of the benzenesulfonyl group resulted in no steric effect in extraction, whereas the existence of two substituents on each ortho-position caused lower extraction performance due to steric hindrance.
\end{abstract}

(Received September 4, 2002; Accepted November 18, 2002)

In chelate extraction, an extractant should have at least one donor atom having negative charge to form a neutral (extractable) complex with a target metal cation. In general, only $-\mathrm{O}^{-}$and $-\mathrm{S}^{-}$have been used as the negatively charged donor. Although an amino group (primary or secondary) has too low acidity to form $>\mathrm{N}^{-}$, sulfonamide group $\left(-\mathrm{NH}-\mathrm{SO}_{2} \mathrm{R}\right)$ has acidity comparable to that of phenolic-OH. ${ }^{1-3}$ From this viewpoint, several researchers have studied the extraction nature of 8-sulfonamidoquinoline derivatives, ${ }^{4-10}$ which are sulfonamide-type analogues of 8-hydroxyquinoline (Hox, a well-known and well-researched bidentate monoanionic extractant).

8-Benzenesulfonamidoquinoline $\quad[N$-(8-quinolyl)benzenesulfonamide, Hbsq] has two aromatic units such as a quinoline ring and a benzene ring (in benzenesulfonyl group). However, there is no report concerning a "distant" substituent effect derived on the latter in the chelate extraction, whereas the "close" substituent effect on the former in Hox has been studied widely. In this research, we investigated the "substituent on benzenesulfonyl group" effect of Hbsq as chelate extractant for divalent metal cations using the following eight derivatives: 8( $p$-toluenesulfonamido)quinoline [4-methyl- $N$-(8-quinolyl)benzenesulfonamide, $\quad \mathrm{H}(p-\mathrm{Me}) \mathrm{bsq}], \quad 8-(2,4,6-$ trimethylbenzenesulfonamido)quinoline $\quad[2,4,6$-trimethyl- $N$ - $(8-$ quinolyl)benzenesulfonamide, $\left.\mathrm{H}\left(2,4,6-\mathrm{Me}_{3}\right) \mathrm{bsq}\right], \quad 8$-(p-tertbutylbenzenesulfonamido)quinoline [4-(dimethylethyl)- $N$-(8quinolyl)benzenesulfonamide, $\quad \mathrm{H}(p-t-\mathrm{Bu}) \mathrm{bsq}], \quad 8-(p-$ chlorobenzenesulfonamido)quinoline [4-chloro- $N$-(8-quinolyl)-

† To whom correspondence should be addressed.

E-mail: hirayama@cacheibm.s.kanazawa-u.ac.jp benzenesulfonamide, $\quad \mathrm{H}(p-\mathrm{Cl}) \mathrm{bsq}], \quad 8-(o-, \quad m-, \quad$ or $\quad p-$ nitrobenzenesulfonamido)quinoline $[2-, 3-$, or 4-nitro- $N-(8-$ quinolyl)benzenesulfonamide, $\mathrm{H}\left(o-, m-\right.$, or $\left.p-\mathrm{NO}_{2}\right)$ bsq] and 8 (2,4-dinitrobenzenesulfonamido)quinoline $\quad[2,4-$ dinitro- $N$ - $(8-$ quinolyl)benzenesulfonamide, $\mathrm{H}\left(2,4-\left(\mathrm{NO}_{2}\right)_{2}\right) \mathrm{bsq}$. Figure 1 shows the chemical structures of these 9 extractants. As a result, it was found that introduction of electron-withdrawing substituent on the benzenesulfonyl group in Hbsq enhances the extractability that originated from its inductive effect. Furthermore, it was found that $a$ bulky substituent on an orthoposition of the benzenesulfonyl group results in no steric effect

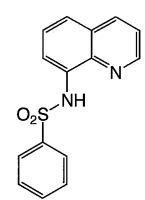

Hbsq
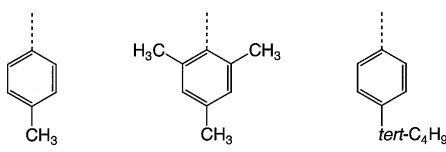

$\mathrm{H}(p-\mathrm{Me}) \mathrm{bsq} \quad \mathrm{H}\left(2,4,6-\mathrm{Me}_{3}\right) \mathrm{bsq} \quad \mathrm{H}(p-t-\mathrm{Bu}) \mathrm{bsq}$<smiles>O=[N+]([O-])c1ccccc1I</smiles>

$\mathrm{H}\left(\mathrm{o}-\mathrm{NO}_{2}\right) \mathrm{bsq}$<smiles>O=[N+]([O-])c1cccc(I)c1</smiles><smiles>O=[N+]([O-])c1ccc(I)cc1</smiles><smiles>O=[N+]([O-])c1ccc(I)c([N+](=O)[O-])c1</smiles>

$\mathrm{H}\left(m-\mathrm{NO}_{2}\right) \mathrm{bsq}$

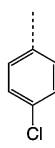

$\mathrm{H}(p-\mathrm{Cl}) \mathrm{bsq}$
Fig. 1 Chemical structures of Hbsq and its derivatives that were used in this study as extractants. 


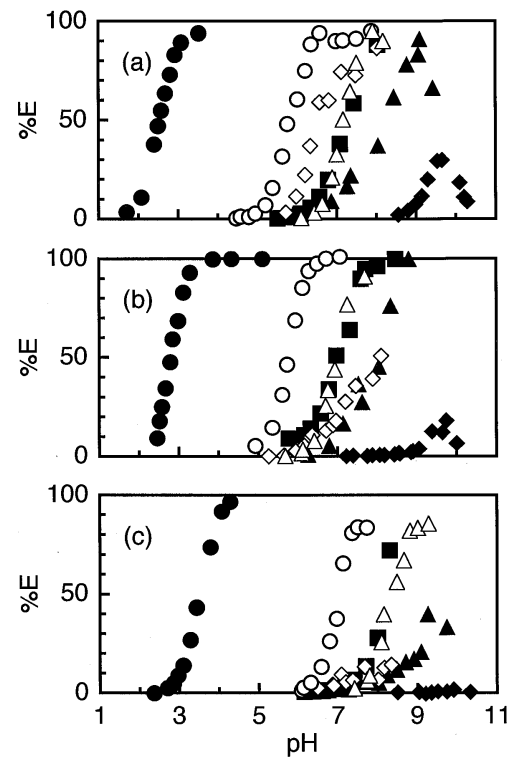

Fig. 2 Plots of the extracted ratios $(\% E)$ for some divalent metals as a function of the aqueous phase $\mathrm{pH}$ equilibrated with organic phase (chloroform) in Hbsq (A), $\mathrm{H}(p$-Me)bsq (B) and $\mathrm{H}(2,4,6-$ $\mathrm{Me}_{3}$ )bsq (C) systems. Initial ligand concentration in chloroform was $1 \times 10^{-3} \mathrm{~mol} \mathrm{dm}^{-3} . \bullet, \mathrm{Mn}^{2+} ; \mathbf{\square}, \mathrm{Co}^{2+} ; \mathbf{\Lambda}, \mathrm{Ni}^{2+} ; \bullet, \mathrm{Cu}^{2+} ; \mathrm{O}, \mathrm{Zn}^{2+} ; \Delta$, $\mathrm{Cd}^{2+} ; \diamond, \mathrm{Pb}^{2+}$.

in extraction, whereas the existence of two substituents on each ortho-position can be a origin of lowering extraction performance by steric hindrance.

\section{Experimental}

\section{Apparatus}

A Hitachi Model Z-6100 polarized Zeeman atomic absorption spectrophotometer was used for the determination of the concentration of a metal in aqueous solution. A Horiba Model F-12 pH meter equipped with a Horiba 9610-10D combined glass electrode was used to determine the $\mathrm{pH}$ values.

\section{Reagents}

The synthesis of $\mathrm{H}(p-\mathrm{Me}) \mathrm{bsq}$ was performed from 8aminoquinoline and $p$-toluenesulfonyl chloride according to the reported procedure. ${ }^{11}$ Other 8-benzenesulfonamidoquinoline derivatives were prepared in a similar manner to $\mathrm{H}(p-\mathrm{Me}) \mathrm{bsq}$ from 8-aminoquinoline and the respective substituted benzenesulfonyl chlorides. The structures were identified by ${ }^{1} \mathrm{H}-\mathrm{NMR}$ spectra and elemental analysis.

All other chemicals were reagent-grade materials and distilled deionized water was used throughout.

\section{Distribution of the metals}

The distribution of metal ions was studied as follows: In a centrifuge tube, an aliquot of chloroform $\left(5 \mathrm{~cm}^{3}\right)$ containing $1 \times$ $10^{-3} \mathrm{~mol} \mathrm{dm}^{-3}$ of a ligand and equal volume of an aqueous phase containing $1 \times 10^{-5}-1 \times 10^{-4} \mathrm{~mol} \mathrm{dm}^{-3}$ of $\mathrm{M}^{2+}(\mathrm{M}=\mathrm{Mn}, \mathrm{Co}, \mathrm{Ni}$, $\mathrm{Cu}, \mathrm{Zn}, \mathrm{Cd}$ or $\mathrm{Pb}), 1 \times 10^{-1} \mathrm{~mol} \mathrm{dm}{ }^{-3}$ of potassium nitrate and 1 $\times 10^{-2} \mathrm{~mol} \mathrm{dm}^{-3}$ of the buffer [chloroacetic acid, acetic acid, 2morpholinoethanesulfonic acid (MES), 3-morpholinopropanesulfonic acid (MOPS) and $N$-tris(hydroxymethyl) methyl-3-aminopropanesulfonic acid (TAPS)] having no influence on the extraction, were shaken at $25 \pm 1^{\circ} \mathrm{C}$ for $2-4 \mathrm{~h}$
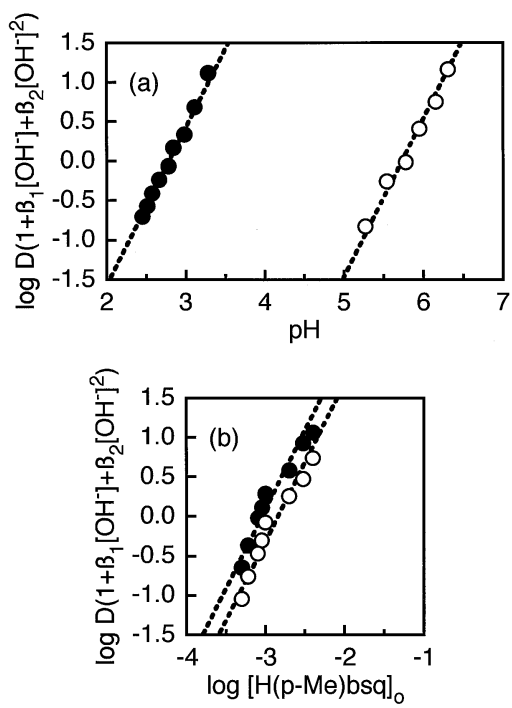

Fig. 3 Plots of $\log D\left(1+\beta_{1}\left[\mathrm{OH}^{-}\right]+\beta_{2}\left[\mathrm{OH}^{-}\right]^{2}\right)$ for $\mathrm{Cu}^{2+}$ and $\mathrm{Zn}^{2+}$ into chloroform in $\mathrm{H}(p-\mathrm{Me})$ bsq system as a function of the aqueous phase $\mathrm{pH}(\mathrm{A})$ and those as a function of the logarithmic concentration of $\mathrm{H}(p-\mathrm{Me}) \mathrm{bsq}$ in organic phase (B). Initial concentration of $\mathrm{H}(p$ Me)bsq was $1 \times 10^{-3} \mathrm{~mol} \mathrm{dm}{ }^{-3}$ on $(\mathrm{A})$, and $\mathrm{pH}$ was $2.7\left(\mathrm{Cu}^{2+}\right)$ and 5.5 $\left(\mathrm{Zn}^{2+}\right)$ on (B). The broken line, of which the slope is 2, was obtained by the least squares fitting. $\bullet, \mathrm{Cu}^{2+} ; \mathrm{O}, \mathrm{Zn}^{2+}$.

(All of the extractions were equilibrated within $1 \mathrm{~h}$, except the one for $\mathrm{Ni}^{2+}$ was within $3 \mathrm{~h}$ ). After the two phases were separated by centrifugation, the $\mathrm{pH}$ and the metal concentration in the aqueous phase were determined and the measured $\mathrm{pH}$ was used as the equilibrated $\mathrm{pH}$. The metal concentration in the organic phase was determined after back-extraction into $1 \mathrm{~mol}$ $\mathrm{dm}^{-3}$ nitric acid.

\section{Results and Discussion}

\section{General extraction selectivity}

The extracted ratios $(\% E)$ of some divalent metals into chloroform with $\mathrm{Hbsq}, \mathrm{H}(p-\mathrm{Me})$ bsq and $\mathrm{H}\left(2,4,6-\mathrm{Me}_{3}\right)$ bsq were plotted as a function of the aqueous phase $\mathrm{pH}$ equilibrated with the organic phase in Fig. 2 as examples. All the studied ligands showed similar extraction selectivity for the divalent metal cations except $\mathrm{Pb}^{2+}$ as follows: $\mathrm{Cu}^{2+} \gg \mathrm{Zn}^{2+}>\mathrm{Cd}^{2+} \approx \mathrm{Co}^{2+}>\mathrm{Ni}^{2+}$ $\gg \mathrm{Mn}^{2+}$. The relatively high extractability for $\mathrm{Zn}^{2+}$ and the low one for $\mathrm{Ni}^{2+}$ seem to be common to ligands having sulfonamide$\mathrm{N}$-donor(s) as reported previously. ${ }^{12}$ In addition, relatively low extraction velocity for $\mathrm{Ni}^{2+}$ agreed with a previous report using $\mathrm{H}(p-\mathrm{Me})$ bsq and $\mathrm{H}\left(2,4,6-\mathrm{Me}_{3}\right)$ bsq in chlorobenzene. ${ }^{8}$

The extraction equilibrium for $\mathrm{M}^{2+}$ on using the sulfonamidetype ligands may be assumed to follow this reaction:

$$
\mathrm{M}^{2+}+2 \mathrm{HL}_{\mathrm{o}} \rightleftharpoons \mathrm{ML}_{2 \mathrm{o}}+2 \mathrm{H}^{+}
$$

where subscript o denotes the species in the organic (chloroform) phase and HL denotes a ligand. In this case, the extraction constant $\left(K_{\mathrm{ex}}\right)$ can be expressed as follows:

$$
K_{\mathrm{ex}}=\left[\mathrm{ML}_{2}\right]_{\mathrm{o}}\left[\mathrm{H}^{+}\right]^{2 /} /\left[\mathrm{M}^{2+}\right][\mathrm{HL}]_{\mathrm{o}}^{2}
$$

In this case, the distribution ratio $(D)$ of $\mathrm{M}^{2+}$ can be expressed as follows: 
Table 1 Log $K_{\text {ex }}$ values determined for divalent metal cations $\left(25 \pm 1^{\circ} \mathrm{C}\right)$

\begin{tabular}{|c|c|c|c|c|c|}
\hline Cation & Hbsq & $\mathrm{H}(p-\mathrm{Me}) \mathrm{bsq}$ & $\mathrm{H}\left(2,4,6-\mathrm{Me}_{3}\right) \mathrm{bsq}$ & $\mathrm{H}(p-t-\mathrm{Bu}) \mathrm{bsq}$ & $\mathrm{H}(p-\mathrm{Cl}) \mathrm{bsq}$ \\
\hline $\mathrm{Mn}^{2+}$ & N.D. ${ }^{a}$ & N.D. ${ }^{a}$ & N.D. ${ }^{a}$ & N.D. ${ }^{\mathrm{a}}$ & N.D. ${ }^{a}$ \\
\hline $\mathrm{Co}^{2+}$ & $-8.21 \pm 0.08$ & $-7.93 \pm 0.13$ & $-10.30 \pm 0.10$ & $-8.62 \pm 0.05$ & $-8.35 \pm 0.12$ \\
\hline $\mathrm{Ni}^{2+}$ & $-10.77 \pm 0.12$ & $-10.39 \pm 0.36$ & N.D. ${ }^{a}$ & N.D. ${ }^{a}$ & $-9.14 \pm 0.29$ \\
\hline $\mathrm{Cu}^{2+}$ & $0.97 \pm 0.03$ & $0.44 \pm 0.04$ & $-0.97 \pm 0.04$ & $0.35 \pm 0.06$ & $0.57 \pm 0.08$ \\
\hline $\mathrm{Zn}^{2+}$ & $-5.73 \pm 0.07$ & $-5.54 \pm 0.04$ & $-7.90 \pm 0.11$ & $-5.88 \pm 0.13$ & $-5.37 \pm 0.09$ \\
\hline $\mathrm{Cd}^{2+}$ & $-8.28 \pm 0.03$ & $-8.42 \pm 0.02$ & $-10.73 \pm 0.02$ & $-8.62 \pm 0.01$ & $-7.93 \pm 0.12$ \\
\hline $\mathrm{Pb}^{2+}$ & $-6.75 \pm 0.10$ & $-7.34 \pm 0.04$ & N.D. ${ }^{a}$ & $-7.38 \pm 0.04$ & $-7.01 \pm 0.03$ \\
\hline Cation & $\mathrm{H}\left(o-\mathrm{NO}_{2}\right) \mathrm{bsq}$ & $\mathrm{H}\left(m-\mathrm{NO}_{2}\right) \mathrm{bsq}$ & $\mathrm{H}\left(p-\mathrm{NO}_{2}\right) \mathrm{bsq}$ & $\mathrm{H}\left(2,4-\left(\mathrm{NO}_{2}\right)_{2}\right) \mathrm{bsq}$ & \\
\hline $\mathrm{Mn}^{2+}$ & $-12.52 \pm 0.03$ & $-11.92 \pm 0.07$ & $-12.12 \pm 0.03$ & $-11.57 \pm 0.07$ & \\
\hline $\mathrm{Co}^{2+}$ & $-7.42 \pm 0.03$ & $-7.00 \pm 0.10$ & $-7.04 \pm 0.06$ & $-6.56 \pm 0.09$ & \\
\hline $\mathrm{Ni}^{2+}$ & $-7.28 \pm 0.12$ & $-8.41 \pm 0.04$ & $-8.18 \pm 0.13$ & $-7.50 \pm 0.17$ & \\
\hline $\mathrm{Cu}^{2+}$ & $0.88 \pm 0.05$ & $-1.66 \pm 0.06$ & $1.56 \pm 0.05$ & $2.12 \pm 0.02$ & \\
\hline $\mathrm{Zn}^{2+}$ & $-4.96 \pm 0.02$ & $-4.28 \pm 0.04$ & $-5.36 \pm 0.05$ & $-4.14 \pm 0.05$ & \\
\hline $\mathrm{Cd}^{2+}$ & $-7.38 \pm 0.04$ & $-7.02 \pm 0.03$ & $-7.22 \pm 0.05$ & $-6.41 \pm 0.05$ & \\
\hline $\mathrm{Pb}^{2+}$ & $-6.03 \pm 0.05$ & $-6.12 \pm 0.04$ & $-6.37 \pm 0.04$ & $-5.06 \pm 0.04$ & \\
\hline
\end{tabular}

a. Not determined because of low extractability.

$$
\begin{aligned}
D & =\left[\mathrm{ML}_{2}\right]_{\mathrm{o}} /\left(\left[\mathrm{M}^{2+}\right]+\left[\mathrm{M}(\mathrm{OH})^{+}\right]+\left[\mathrm{M}(\mathrm{OH})_{2}\right]\right) \\
& =\left(\left[\mathrm{ML}_{2}\right]_{\mathrm{o}} /\left[\mathrm{M}^{2+}\right]\right)\left(1+\beta_{1}\left[\mathrm{OH}^{-}\right]+\beta_{2}\left[\mathrm{OH}^{-}\right]^{2}\right)^{-1} \\
& =\left(K_{\mathrm{ex}}[\mathrm{HL}]_{0}^{2} /\left[\mathrm{H}^{+}\right]^{2}\right)\left(1+\beta_{1}\left[\mathrm{OH}^{-}\right]+\beta_{2}\left[\mathrm{OH}^{-}\right]^{2}\right)^{-1}
\end{aligned}
$$

where $\beta_{1}$ and $\beta_{2}$ are stability constants for hydroxo complexes of $\mathrm{M}(\mathrm{OH})^{+}$and $\mathrm{M}(\mathrm{OH})_{2}$, respectively. From Eq. (3), validity of Eq. (1) can be confirmed by plotting $\log D\left(1+\beta_{1}\left[\mathrm{OH}^{-}\right]+\right.$ $\left.\beta_{2}\left[\mathrm{OH}^{-}\right]^{2}\right)$ vs. $\mathrm{pH}$ at fixed $[\mathrm{HL}]_{\mathrm{o}}$ and plotting $\log D\left(1+\beta_{1}\left[\mathrm{OH}^{-}\right]\right.$ $\left.+\beta_{2}\left[\mathrm{OH}^{-}\right]^{2}\right)$ vs. $\log [\mathrm{HL}]_{0}$ at fixed $\mathrm{pH}$ (The following $\beta_{i}$ values for $\mathrm{Mn}^{2+}, \mathrm{Co}^{2+}, \mathrm{Ni}^{2+}, \mathrm{Cu}^{2+}, \mathrm{Zn}^{2+}, \mathrm{Cd}^{2+}$ and $\mathrm{Pb}^{2+}$ were used for the calculation in this section: $\log \beta_{1}=3.404 .35,4.14,6.30,5.04$, 3.92 and 6.29, and $\log \beta_{2}=5.80,9.19,9.00,10.70,11.09,7.64$ and 10.87, respectively). ${ }^{13}$ Figure 3 shows these plots for $\mathrm{Cu}^{2+}$ and $\mathrm{Zn}^{2+}$ on $\mathrm{H}(p-\mathrm{Me})$ bsq system as examples. In all cases, the slope was close to 2 and the extraction equilibrium was found as shown in Eq. (1). In other words, it was found that Hbsq and its analogues do not form $\mathrm{ML}_{2}(\mathrm{HL})_{n}$ species such as Hox. This seems to be due to the bulkiness of the (substituted) benzenesulfonyl group.

The $\log K_{\text {ex }}$ values calculated from experimental data using Eq. (3) are shown in Table 1. In this calculation, distribution of HL into aqueous phase was negligible because of its high hydrophobicity.

\section{"Substituent on benzenesulfonyl group" effect}

As shown in Table 1, introduction of para-alkyl substituent onto the benzenesulfonyl group in Hbsq (ex. $\mathrm{H}(p-\mathrm{Me})$ bsq and $\mathrm{H}(p-t-\mathrm{Bu}) \mathrm{bsq})$ lead to hardly any enhancement in extractability or drastical change of extraction selectivity. This result seems to originate from the bulkiness of the benzenesulfonyl group itself. Namely, these substituents contribute little enhancement of the hydrophobicity of the ligands and, therefore, do not improve the stabilization of the extracted species.

Introduction of electron-withdrawing substituent such as $-\mathrm{Cl}$ and $-\mathrm{NO}_{2}$, on the contrary, lead to enhancement in extractability. The effect of the latter was larger than that of the former. Furthermore, $\mathrm{H}\left(2,4-\left(\mathrm{NO}_{2}\right)_{2}\right) \mathrm{bsq}$ showed higher extraction performance than $\mathrm{H}\left(o-\mathrm{NO}_{2}\right)$ bsq and $\mathrm{H}\left(p-\mathrm{NO}_{2}\right) \mathrm{bsq}$, which qualitatively proves that this nature has additive property. These facts suggest that the substituent inductively enhances the acidity of $>\mathrm{NH}$ and thus prompts complexation between the dissociated $>\mathrm{N}^{-}$and metal cations.

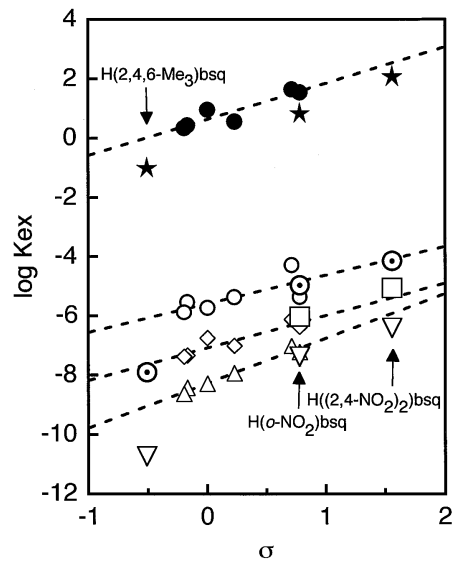

Fig. 4 Plots of the determined $\log K_{\mathrm{ex}} v s$. Hammett $\sigma$ values. $\bullet \star$, $\mathrm{Cu}^{2+} ; \circ \odot, \mathrm{Zn}^{2+} ; \Delta \nabla, \mathrm{Cd}^{2+} ; \diamond \square, \mathrm{Pb}^{2+}$. The broken line was obtained by the least squares fitting using data on Hbsq, $\mathrm{H}(p-\mathrm{Me}) \mathrm{bsq}, \mathrm{H}(p-t$ $\mathrm{Bu}) \mathrm{bsq}, \mathrm{H}(p-\mathrm{Cl}) \mathrm{bsq}, \mathrm{H}\left(m-\mathrm{NO}_{2}\right) \mathrm{bsq}$ and $\mathrm{H}\left(p-\mathrm{NO}_{2}\right)$ bsq (These data were plotted using smaller $\bullet \triangle \diamond$ symbols). On plotting data on $\mathrm{H}\left(2,4,6-\mathrm{Me}_{3}\right) \mathrm{bsq}, \mathrm{H}\left(o-\mathrm{NO}_{2}\right)$ bsq and $\mathrm{H}\left(2,4-\left(\mathrm{NO}_{2}\right)_{2}\right) \mathrm{bsq}$, the values of $3 \sigma_{p-\mathrm{Me}}, \sigma_{p-\mathrm{NO}_{2}}$ and $2 \sigma_{p-\mathrm{NO}_{2}}$, respectively, were used as $\sigma$ (These data were plotted using larger $\star \odot \nabla \square$ symbols).

It is interesting that the effect of $o-\mathrm{NO}_{2}$ substituent was similar to that of $p-\mathrm{NO}_{2}$, showing that of $a$ bulky substituent on an ortho-position of the benzenesulfonyl group results in no steric hindrance on complexation. Possibly, the steric risk is avoided by rotating the benzene ring to the position that the substituent is directed near $\mathrm{S}=\mathrm{O}$ bonds in $>\mathrm{SO}_{2}$ group. To the contrary, lower extractability on the use of $\mathrm{H}\left(2,4,6-\mathrm{Me}_{3}\right)$ bsq suggests that the existence of two substituents on each ortho-position of the benzenesulfonyl group brings on the steric hindrance, which cannot be avoided by the rotation. Namely, the one substituent seems to be not only directed near $>\mathrm{N}^{-}$coordination site but also pushed forward to the site because of steric repulsion between the another substituent and $>\mathrm{SO}_{2}$ group

To evaluate the discussion mentioned above numerically, $\log K_{\text {ex }} v s$. Hammett $\sigma^{14}$ plots were produced. Figure 4 shows the plots for $\mathrm{Cu}^{2+}, \mathrm{Zn}^{2+}, \mathrm{Cd}^{2+}$ and $\mathrm{Pb}^{2+}$ as examples. The data on six extractants, Hbsq, $\mathrm{H}(p-\mathrm{Me}) \mathrm{bsq}, \mathrm{H}(p-t-\mathrm{Bu}) \mathrm{bsq}, \mathrm{H}(p-\mathrm{Cl}) \mathrm{bsq}$, 
$\mathrm{H}\left(m-\mathrm{NO}_{2}\right)$ bsq and $\mathrm{H}\left(p-\mathrm{NO}_{2}\right) \mathrm{bsq}$, were used for the determination of regression lines. The determined lines showed similar slopes $\left(0.97-1.51\right.$, except for $\left.\mathrm{Ni}^{2+}(2.59)\right)$ and relatively high correlation coefficients $\left(0.843-0.972\right.$, except for $\mathrm{Co}^{2+}$ (0.770) and $\left.\mathrm{Zn}^{2+}(0.542)\right)$, demonstrating the inductive effect. Furthermore, the data on $\mathrm{H}\left(o-\mathrm{NO}_{2}\right)$ bsq (using $\sigma_{p-\mathrm{NO}_{2}}$ as $\sigma$ ) and on $\mathrm{H}\left(2,4-\left(\mathrm{NO}_{2}\right)_{2}\right)$ bsq (using $2 \sigma_{p-\mathrm{NO}_{2}}$ as $\sigma$ ) were placed close to the regression lines, whereas those on $\mathrm{H}\left(2,4,6-\mathrm{Me}_{3}\right) \mathrm{bsq}$ (using $3 \sigma_{p \text {-Me }}$ as $\sigma$ ) were placed far from them. This fact supports the above-mentioned discussion concerning steric effect.

As conclusive words, we points out that the "substituent on benzenesulfonyl group" effect studied here is obviously not peculiar to Hbsq but will be common to any ligands having benzenesulfonamide group. That is to say, the inductive effect and the steric effect mentioned above can be a factor to control extraction performance of all of the benzenesulfonamide-type ligands.

\section{Acknowledgements}

This study was financially supported in part by Grant-in-Aid for Scientific Research No. 13740420 from the Ministry of Education, Culture, Sports, Science and Technology, Japan.

\section{References}

1. Y. Moriguchi, T. Yoshimatsu, M. Takagi, and K. Ueno,
Bunseki Kagaku, 1982, 31, 318.

2. H. Nakamura, T. Yoshida, M. Todoko, K. Ueno, and M. Takagi, Bull. Chem. Soc. Jpn., 1984, 57, 2839.

3. Y. Moriguchi, T. Yoshida, and M. Takagi, Bunseki Kagaku, 1984, 33, 435.

4. M. Takagi, T. Omori, S. Matsuo, S. Matsuno, K. Ueno, and S. Ide, Chem. Lett., 1980, 387.

5. Y. C. Hoh and C. H. Wang, J. Chem. Technol. Biotechnol., $\mathbf{1 9 8 1}, 31,345$.

6. C. H. Wang and Y. C. Hoh, Hydrometallurgy, 1982, 8, 161.

7. S. Ide, T. Yoshida, S. Matsuno, M. Takagi, and K. Ueno, Anal. Chim. Acta, 1983, 149, 235.

8. S. Ide and M. Takagi, Anal. Sci., 1986, 2, 265.

9. K. Yoshizuka, K. Kondo, and F. Nakashio, J. Chem. Eng. Jpn., 1986, 19, 396.

10. J. M. Castresana, M. P. Elizalde, M. Aguilar, and M. Cox, Chem. Scr., 1987, 27, 273.

11. J. H. Billman and R. Chernin, Anal. Chem., 1962, 34, 408.

12. N. Hirayama, J. Taga, S. Oshima, and T. Honjo, Anal. Chim. Acta, 2002, 466, 295.

13. S. Kotrlý and L. S̆ůcha, "Handbook of Chemical Equilibria in Analytical Chemistry", 1985, Ellis Horwood, Chichester.

14. J. E. Leffler and E. Grunwald, "Rates and Equilibria of Organic Reactions", 1963, John Wiley and Sons, New York and London. 